\title{
Osteoporosis after spinal cord injury
}

\author{
Gülçin Demirel, Hürriyet Yilmaz, Nurdan Paker and Selma Önel \\ Istanbul Physical Medicine and Rehabilitation Centre, Istanbul, Turkey
}

\begin{abstract}
Immobilisation secondary to spinal cord injury (SCI) is associated with marked and rapid atrophy of trabecular bone. The purpose of this study was to evaluate bone mineral density (BMD) in both the upper and lower extremities following SCI sustained for various lengths of time and to correlate the BMD to the level of the lesion, time from injury, spasticity and serum calcium, phosphorus and alkaline phosphatase (ALP) levels. A study was undertaken in 41 SCI patients with a mean age of $35.8 \pm 12.7$ years. A significant difference in BMD between upper and lower extremities of the paraplegics were found. BMD of upper and lower extremities were similar in tetraplegies. The BMD values were significantly different when the upper extremity scores of paraplegics and tetraplegics were compared but BMD scores of the lower extremities were similar in the two groups. The decrease in BMD was less in the spastic patients when compared to the flaccid group. There was a positive correlation between time from injury and the degree of BMD deficit in the paralysed areas. In the whole group of patients a significant positive correlation was found between the duration of SCI and serum ALP levels.
\end{abstract}

Keywords: osteoporosis-spinal cord injury; bone mineral density (BMD); dual energy X-ray absorptiometry (DEXA); biochemical markers

\section{Introduction}

Immobilisation following SCI is a condition known to be associated with a decrease in bone mass, osteopenia and sometimes leading to osteoporosis with an increased risk of fractures. In this condition, previous histomorphometric and biochemical reports have shown an uncoupling between bone formation and resorption, but the exact sequence of the events resulting in bone loss is still not fully understood. ${ }^{1-4}$ Most authors agree that major bone loss occurs during the first 6 months after SCI and stabilises between $12-$ 16 months at two thirds of the original bone mass. ${ }^{2}$ Some investigators suggest that immediately after SCI the balance between bone resorption and bone formation tips in favour of resorption. ${ }^{5,6}$ The loss of the normal biomechanical stress associated with some degree of neurovascular changes due to autonomic nervous system activity have metabolic consequences where bone tissue is one of the primary targets. ${ }^{2}$

The purpose of this study was to evaluate bone mineral density (BMD) in both the upper and lower limbs with spinal cord injury sustained for various lengths of time and to correlate BMD to the level of the spinal cord lesion, time from injury, spasticity and serum calcium, phosphorus and alkaline phosphatase levels.

\section{Subjects and methods}

This study was carried out in Istanbul Physical Medicine and Rehabilitation Centre. The sample

Correspondence: G Demirel consisted of 41 patients with spinal cord injury (SCI). All patients were previously healthy. None of the patients had metabolic diseases known to influence their calcium metabolism or BMD and none of the patients received treatment influencing these parameters. Patients with clinical or radiological evidence of heterotopic ossification were excluded from the study. Each patient gave informed consent. The mean age of the group was $35.8 \pm 12.7$ years (range 19-49 years) and the lesion level was from C4 to L3.

Data that were recorded on each patient included age, sex, height, weight, etiology, level of injury (as defined by the American Spinal Injury Association criteria), time from injury, the onset time of rehabilitation and spasticity. The degree of spasticity ranged from grade 0 to grade 4 on the Ashworth Peterson scale.

Bone mineral density was measured by dual energy X-ray absorbtiometry (DEXA) (Lunar Model DPX, Lunar Corp., Madison, WI) in the whole-body composition. In whole-body composition seven different regions of the body are measured. We only used the values for arms and legs. The trunk and lumbar spine measurements were excluded because they were often the site of osteosynthesis material.

The BMD values from Lunar DPX were automatically standardised for age (age-matched) and for young adults (young-matched). All the BMD values cited in the text refer to age standardised (agematched) BMD Z scores unless otherwise stated.

In routine blood chemistry, serum calcium, phosphorus, alkaline phosphatase levels, liver and renal function tests were assessed. 
After equality of variance was tested with Levene's test, appropriate Student's $t$-test was applied. The correlation between two numerical variables were tested with Pearson's bivariate correlation coefficient. Criterion for statistical significance was considered to be $P<0.05$.

\section{Results}

In this study, $41 \mathrm{SCI}$ patients were registered from August 1995 to February 1996. Their mean age at the time of injury was $34.5 \pm 11.0$ years. There were 32 $(78 \%)$ males and $9(22 \%)$ females. The mean age of our female patients was $33.2 \pm 10.2$, and of our male patients was $34.4 \pm 9.5$ years. Their median height was $170 \mathrm{~cm}$ (range 161 to $183 \mathrm{~cm}$ ) and median weight was $70.5 \mathrm{~kg}$ (range 55 to $87 \mathrm{~kg}$ ). All our female patients were menstruating.

The level of injury was between $\mathrm{C} 4-\mathrm{C} 7$ in $5(12.2 \%)$, $\mathrm{T} 1-\mathrm{T} 6$ in $6(14.6 \%), \mathrm{T} 7-\mathrm{T} 12$ in $20(48.8 \%)$ and $\mathrm{L} 1-$ L3 in $10(24.4 \%)$. Mean age of the paraplegics was $36.2 \pm 13.1$ and the mean age of the tetraplegics was $33.2 \pm 10.3$ years. Eighteen of the 36 paraplegic patients $(50 \%)$ and three of the five tetraplegic patients $(60 \%)$ had complete lesion.

Etiology of injury was traffic accident in 18 (43.9\%), fall in $10(24.3 \%)$, gunshot wound in four $(9.8 \%)$, water sports and diving in four $(9.8 \%)$, work place accident in two $(4.9 \%)$, infection in two $(4.9 \%)$, and vascular in one $(2.4 \%)$. They had sustained injuries of the spinal cord a mean of $9.5 \pm 4.5$ months (range $2-$ 30 months) previously. The onset of rehabilitation was within 0.5 to 7 months after injury (mean $2.5 \pm 1.9$ months). Thirty-five of the 41 patients $(85.4 \%)$ were spastic, $10(32.3 \%)$ were grade $1,11(35.5 \%)$ were grade 2 , three $(9.6 \%)$ were grade 3 , and three $(9.6 \%)$ were grade 4 .

There was no statistically significant difference between paraplegic and tetraplegic groups in age, sex, height, weight, and spasticity. There was no correlation between the age and the BMD of our patients $(r=-0.13, P>0.05)$. There was no significant difference between the BMD of the male and female patients $(-2.6 \pm 1.48$ versus $-2.13 \pm 1.89$, $P>0.05)$. In paraplegic patients, BMD of the upper extremities was significantly higher than the same scores from tetraplegic patients $(+0.09 \pm 0.15$ versus $-0.87 \pm 0.84, P<0.01)$. There was a considerable fall in lower extremity BMD values in paraplegics and tetraplegics but the difference between the groups was not significant $(-2.19 \pm 3.5$ versus $-2.50 \pm 0.55$, $P<0.05)$. In paraplegic patients upper extremity BMD scores were significantly higher than the lower extremity BMD values $(0.09 \pm 0.15$ versus $-2.19 \pm 0.32, \quad P<0.001)$. There was no statistically significant difference between upper and lower extremity BMD values in tetraplegic patients $-0.87 \pm 0.84$ versus $-2.50 \pm 0.55, \quad P=0.102)$. The BMD values of arms and legs of the SCI patients are shown in Figure 1.
There was a statistically significant difference in BMD between complete and incomplete SCI patients. In complete SCI, osteopenia was more apparent $(-2.29 \pm 0.51$ versus $-0.12 \pm 0.22, \quad P<0.05)$. The patients with spasticity had higher BMD when compared with flaccid patients $(+0.078 \pm 0.62$ versus $-0.118 \pm 0.46, P<0.05)$.

In paraplegic groups, there was no correlation between time from injury and degree of BMD deficit in the upper extremity $(r=-0.06, P>0.05)$, but there was a strong correlation of time from injury to the degree of BMD deficit in the lower extremities $(r=-0.80, P<0.001)$.

In tetraplegic groups, there was a negative and moderate correlation between time from injury and degree of BMD deficit in lower extremities $(r=-0.42$, $P=0.005)$ (Figure 2).

Serum calcium $(10.1 \pm 0.8 \mathrm{mg} / \mathrm{dl})$, phosphorus $(4.0 \pm 0.5 \mathrm{mg} / \mathrm{dl})$, liver and renal function tests were normal in our patients. ALP values were moderately

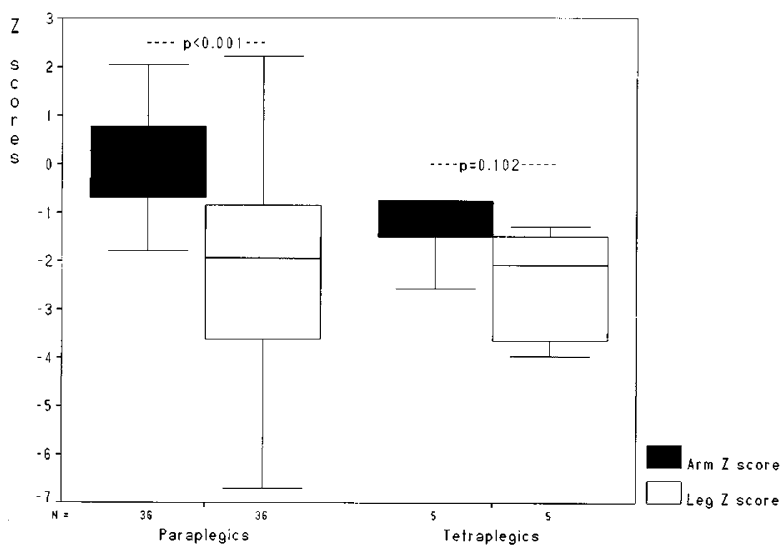

Figure 1 Upper \& lower extremity age matched $\mathrm{Z}$ scores in paraplegics and tetraplegics

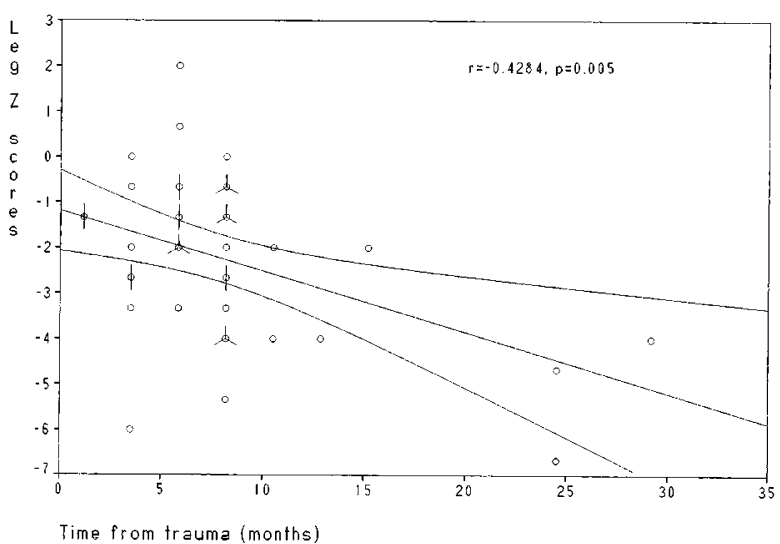

Figure 2 Relation of time from trauma to lower extremity age matched $\mathrm{Z}$ scores 
elevated $(47 \pm 14 \mathrm{U} / \mathrm{lt}$.) when compared to laboratory reference values. When all the patients were pooled, a positive moderate correlation between the duration of SCI and serum ALP was found $(r=+0.48, P=0.001)$ (Figure 3), but not with calcium $(r=-0.25, P>0.05)$ or phosphorus $(r=-0.008, P>0.05)$.

There was no correlation between lower extremity BMD and serum ALP in SCI patients $(r=-0.23$, $P=0.151$ ) (Figure 4). We found no correlation between total body BMD and serum calcium $(r=-0.17, \quad P=0.27) \quad$ or phosphorus $\quad(r=-0.24$, $P=0.12)$.

\section{Discussion}

Loss of bone in the paralysed areas is a well known complication of spinal cord injury. ${ }^{6-9}$ Immobility results in a parallel loss of muscle and bone. Bone is exposed to constantly changing patterns of loading and adapts to these changes through alterations in bone

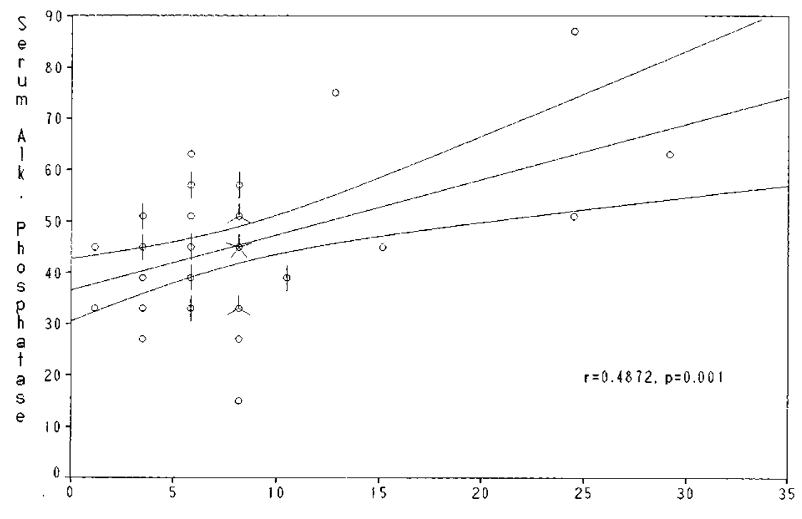

Time from trauma (months)

Figure 3 Relation of serum alkaline phosphatase level to time from trauma

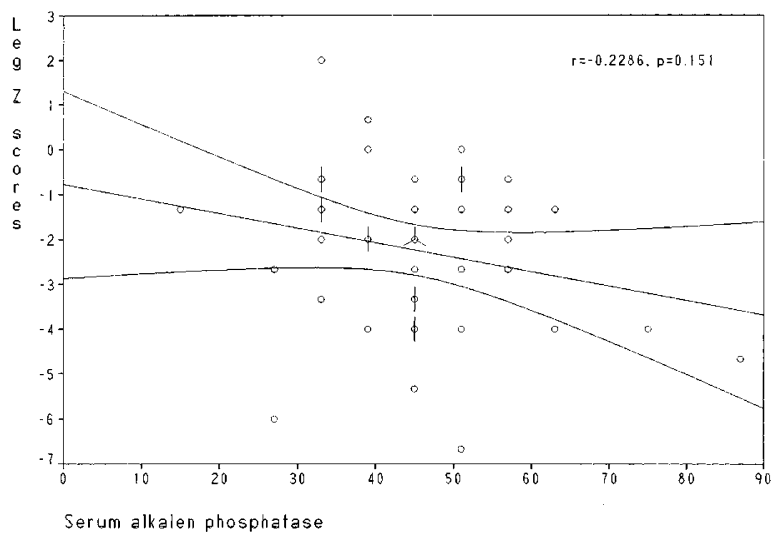

Figure 4 Relation of lower extremity age matched $\mathrm{Z}$ scores to serum alkaline phosphatase levels mass and skeletal structure. ${ }^{10-12}$ Our results are confirmatory that an appreciable amount of bone is lost rapidly in the paralysed areas after spinal cord injury.

Biering-Sorensen et $a l^{3}$ have observed in a 3 year prospective study, a $50 \%$ decrease in BMD in paralysed limbs of SCI patients. Garland et $a l^{5}$ reported that decreases of BMD of femur can be detected through the period 4-16 months after SCI, with a plateau thereafter. Finsen et $a l^{13}$ showed the degree of osteoporosis in the paralysed limbs increased with the time since injury. In our study BMD deficit in the paralysed segment increased with time and the increase was more prominent in complete injury. The discrepancies between studies may be due to the time of commencement of the rehabilitation program, rehabilitation intensity and the differences between patient populations.

Garland et $a l^{5}$ had shown that there was significant difference in the BMD values of the arms of the tetraplegic and paraplegic patients. In our study we observed that bone mineral loss in the upper extremities of tetraplegics was higher than that observed in paraplegics.

Bone loss after SCI has been related to the severity of the injury and the degree to which patients were able to ambulate. ${ }^{14}$ Saizstein et $a l^{15}$ found lower than average BMD in motor complete subjects compared to incomplete subjects and found that bone loss was correlated to a subject's 'mobility index'. In our study complete SCI patients had greater BMD loss than incomplete patients and lower extremity BMD loss was more important in tetraplegics when compared to paraplegics. BMD losses were mainly in the lower extremities in the paraplegic and tetraplegic patients. The finding of a much more pronounced osteopenia in the paralysed lower limbs than the paralysed upper limbs has been reported previously. ${ }^{13}$

Biering-Sorensen et $\mathrm{al}^{16}$ showed that BMD of the femoral bone was continuously and significantly decreased in SCI patients aged between 20-55 compared to healthy individuals, while BMD of the lumbar spine was nearly unchanged. Szollar et al ${ }^{17}$ showed that during the first year of injury patients between the age of 20-59 displayed a non significant decrease in the BMD's of the spine and the hip regions. The patients older than 60 years had a nonsignificant increase in the BMD's of the spine and hip regions during this time. ${ }^{17}$ We noticed no relation between age and sex of the patients and BMD loss. This may be related to the youth of our patients and the premenopausal status of our female patients.

Wilmet et $a t^{4}$ reported that spasticity or flaccidity had no effect on BMD loss in the paralysed areas. But in our study, patients with spasticity had lesser BMD loss compared to flaccid patients. The BMD deficit was decreased by the increase in spasticity. This may mean that spasticity is protective against BMD loss.

Burr and Neuseibeh et $a l^{18}$ found no significant differences in either serum calcium or phosphate values 
in the paraplegics and controls they studied. ClausWalker et $a l^{19}$ evaluated 32 tetraplegic patients and found that levels of calcium and phosphorus were elevated within days after injury and remained elevated as long as 18 months. Finsen et l $^{13}$ found no significant differences in the levels of serum ALP and calcium. Van der Wiel et $a l^{20}$ reported increased serum calcium and phosphorus during immobilisation and total ALP did not vary during the immobilisation period. Pietschmann et $a l^{2}$ reported normal values in serum calcium and phosphorus levels in SCI patients. We found no significant difference in serum calcium and phosphorus levels but moderately higher levels of ALP in SCI patients.

It has been shown that in immobilisation osteoporosis, with a marker of increased osteoblastic activity like ALP, osteocalcin is increased. ${ }^{21,22}$ The observation of an increase in ALP in our patient group denotes increased bone formation. But the observed decrease in BMD implies the increase in bone formation does not catch up with bone resorption.

\section{References}

1 Chappard D et al. Effects of tiludronate on bone loss in paraplegic patients. J Bone \& Mineral Res 1995; 10: $112-118$.

2 Uebelhart D, Demiaux Domenech B, Roth M, Chantraine A. Bone metabolism in spinal cord injured individuals and in others who have prolonged immobilization. A review. Paraplegia 1995; 33: $669-673$.

3 Biering-Soransen F, Bohr H, Schaadt OP. Longitudinal study of bone mineral content in the lumbar spine, the forearm and the lower extremities after spinal cord injury. Eur J Clin Invest 1991; 20: $330-335$.

4 Wilmet E, lsmail AA, Hilporn A, Welroads D. Longitudinal study of bone mineral content and soft tissue composition after spinal cord section. Paraplegia 1995; 33: 674-677.

5 Gariand DE et al. Osteoporosis after spinal cord injury. $J$ Orth Res. 1992; 10: $371-378$.
6 Sobel M, Lyden JP. Long bone fracture in a spinal cord injured patient: complication of treatment. A case report and review of the literature. J Trauma 1991; 31: 1440-1444.

7 Sinaki M. Rehabilitation Medicine. Principles and practice In: De Lisa JA, Gans BM (eds.), 2nd edn. JB Lippincott Company; Philadelphia 1993, pp $1018-1035$

8 Goomaera S, Van Laere M, De Neve P, Kaufman JM. Bone mineral status in paraplegic patients who do or do not perform standing. Osteoporosis lnt 1994; 4: $138-143$.

9 Elia AN, Gwinup G. Immobilization osteoporosis in paraplegia J Am Paraplegia Soc 1992; 15: 163 - 170.

10 Keating JF, Kerr M, Delargy M. Minimal trauma causing fractures in patients with spinal cord injury. Disability \& Rehab 1992; 14: $108-109$.

11 Schoulens A et al. Bone loss and bone blood flow in paraplegic rats treated with calcitonin, diphosphonate and indomethacine. Calcif Tissue Int 1988; 42: 136-143.

12 Chantraine A, Nusgens B, Lapiere CM. Bone remodeling during the development of osteoporosis in paraplegia. Calcif Tissue lnt 1986; 38: 323 - 327.

13 Finsen V, Intredavic B, Fougner KJ. Bone mineral and hormone status in paraplegics. Paraplegia 1992; 30: 343 - 347.

14 Kaplan PE et al. Reduction of hyperalciuria in tetraplegia after weight bearing and strengthening exercises. Paraplegia 1981; 19: $289-293$.

15 Saiztein RJ, Hardin S, Hastings J. Osteoporosis in spinal cord injury: using an index of mobility and its relationship to bone density. J Am Paraplegia Soc 1992; 15: 232-234.

16 Biering-Sorensen F, Bohr H, Schaadt O. Bone mineral content of the lumbar spine and lower extremities years after spinal cord lesion. Paraplegia 1988; 26: 293 - 301 .

17 Szollar SM et al. Densitometric patterns of spinal cord injury associated bone loss. Spinal Cord 1997; 35: 374-382.

18 Burr RG, Nuseibeh I. Biochemical studies in paraplegic renal stone patients. Br J Urol 1985; 57: $269-274$.

19 Claus Walker $\mathbf{J}$ et al. Bone metabolism in quadriplegia: dissociation between calcium and hydroxyprolinuria. Arch Phys Med Rehabil 1975; 56: $327-332$.

20 Van der Wiel HE et al. Biochemical parameters of bone turnover during ten days of bed rest and subsequent mobilization. Bone Mineral 1991; 13: $123-129$.

21 Pietschmann $\mathrm{P}$ et al. Increased serum osteocalcin levels in patients with paraplegia. Paraplegia 1992; 30: 204-209.

22 Kanis JA. Assessment of bone mass and osteoporosis In: Kanis JA (ed). Osteoporosis Rev edn. Blackwell Health Care Communication: London 1997 pp 114-147. 